\title{
Is Renal Impairment an Anticipated COPD Comorbidity?
}

\author{
Hesham A AbdelHalim MD and Heba H AboElNaga MD
}

\begin{abstract}
BACKGROUND: Many studies have investigated COPD-linked comorbidities and their influence on associated outcomes, but the extent to which COPD is related to chronic renal failure is undetermined. The objective of this work was to assess the prevalence of chronic renal failure (overt or concealed) in a cohort with COPD compared with that of a control group, and to investigate the relationships of the clinical and functional data with the subjects' renal conditions. METHODS: The study was performed with 136 subjects with COPD and 104 control subjects. The subjects with COPD were divided into 2 groups according to a combined assessment. The COPD and control groups were compared in terms of clinical factors, renal function, estimated glomerular filtration rate, and spirometry data. The prevalence of the renal status types was examined in all groups, and the correlations of serum creatinine and estimated glomerular filtration rate with all of the clinical and spirometry data were examined. RESULTS: There were significant differences between both COPD groups and the controls regarding estimated glomerular filtration rate. Significantly worse renal function was observed in the COPD group, which also exhibited a greater percentage of subjects with concealed chronic renal failure. Additionally, there were significant differences in renal status among the 3 groups; the percentage of subjects with concealed chronic renal failure was significantly greater in group 2 than in both group 1 and the control group. Additionally, the percentages of subjects with concealed chronic renal failure were greater than those with overt chronic renal failure in the 3 groups. There were significant correlations of serum creatinine with COPD assessment test, exacerbations and hospitalizations, percent-of-predicted FVC, percent-ofpredicted $\mathrm{FEV}_{1} / \mathrm{FVC}$, percent-of-predicted maximum mid-expiratory flow, and percent-of-predicted peak expiratory flow. Moreover, there were significant correlations between estimated glomerular filtration rate and all of the clinical and spirometry data. CONCLUSIONS: Chronic renal failure should not be ignored or underestimated in patients with COPD because it frequently cannot be recognized based on serum creatinine because decreases in estimated glomerular filtration rate are more prevalent. Key words: COPD; chronic renal failure; glomerular filtration rate; modification of diet in renal disease (MDRD) equation. [Respir Care 2016;61(9):1201-1206. (C) 2016 Daedalus Enterprises]
\end{abstract}

\section{Introduction}

COPD is expected to be significantly associated with comorbidity, and some studies have reported renal impairments in COPD subjects in selected populations. The diagnosis of kidney disease was self-reported by a surprisingly low percentage $(0.2 \%)$ of subjects with COPD who

\footnotetext{
Dr AbdelHalim is affiliated with the Pulmonary Medicine Department, Faculty of Medicine, Ain Shams University, Cairo, Egypt. Dr AboElNaga is affiliated with the Pulmonary Medicine Department, Faculty of Medicine, October 6 University, Giza, Egypt.
}

The authors have disclosed no conflicts of interest. were studied by van Manen et al. ${ }^{1}$ Other studies have demonstrated that chronic renal failure has a prevalence of $6 \%$ and predicted long-term mortality independent of wellrecognized risk factors. However, in these studies, chronic renal failure was diagnosed based on serum creatinine; therefore, its prevalence was probably underestimated. ${ }^{2}$ However, some studies have recognized that smoking af-

\footnotetext{
Correspondence: Hesham Atef AbdelHalim MD, Pulmonary Medicine, Ain Shams University, 28C, Opera City Compound, Sheikh Zayed, Giza, Egypt. E-mail: heshamatef@med.asu.edu.eg.
}

DOI: $10.4187 /$ respcare.04516 
fects vascular and hormonal systems and is involved in the development of thrombogenesis, atherosclerosis, and vascular occlusions ${ }^{3}$; thus, prolonged smoking negatively affects the prognoses of renal diseases. ${ }^{4}$

Chronic renal failure has recently been determined to be a public health problem. The risk factors for chronic renal failure include an age of $>60 \mathrm{y}$, arterial hypertension, diabetes mellitus, cardiovascular disorders, and a positive family history of the disease.

The glomerular filtration rate is traditionally considered the best overall index of renal function in health and disease in terms of evaluating people with increased risk. ${ }^{5}$ However, because the glomerular filtration rate is difficult to measure in clinical practice, it is typically estimated using an equation that is based on the serum creatinine level. ${ }^{6}$

Different researchers have studied COPD-linked comorbidities $^{5,7-10}$ and their influences on related outcomes, such as health-related quality of life and health burden, ${ }^{1,9}$ but the extent to which COPD-linked comorbidities are linked to chronic renal failure is unknown. Many smoking-related factors have been discovered to be risk factors for kidney diseases. ${ }^{6}$ Additionally, coronary artery disease, which is highly prevalent in patients with COPD, is associated with vascular kidney disease. ${ }^{11}$ Moreover, some studies have suggested that the high prevalence of chronic renal failure in subjects with COPD has important clinical implications. First, chronic renal failure is associated with increased serum levels of inflammatory biomarkers and prothrombotic molecules. Therefore, chronic renal failure might partly mediate the association between COPD and cardiovascular diseases. Second, the link between COPD and anemia might be explained by the accompanying chronic renal failure. Thus, COPD is expected to be significantly associated with chronic renal failure. ${ }^{11}$ Unfortunately, most research that has examined COPD comorbidities has been conducted in populations that exclude those with kidney diseases. ${ }^{12}$ However, within the context of the progressively increasing interest in the systemic manifestations of COPD and related comorbidities, chronic renal failure must not be overlooked or underestimated. The present study aimed to assess the prevalence of both overt and concealed chronic renal failure in a cohort with COPD compared with a control group without the burden of COPD and to investigate the clinical and functional data of these groups in relation to kidney function.

\section{Methods}

The study was performed with 136 male subjects who were recruited from the out-patient departments of pulmonary medicine of Ain Shams University and the October 6 University Hospitals. The patients were diagnosed with COPD based on clinical manifestations and spirometry

\section{QUICK LOOK}

\section{Current knowledge}

The association between COPD and chronic renal failure has not been assessed sufficiently, and the strength of this association is thus unknown. Some studies have shown that COPD is expected to be significantly associated with chronic renal failure. However, most studies that reported the comorbidities of COPD examined specific populations and did not state how chronic renal failure was diagnosed.

\section{What this paper contributes to our knowledge}

This study demonstrated that renal impairment was more prevalent among subjects with COPD than among nonCOPD control subjects without comorbidities. This study also demonstrated the importance of estimating the glomerular filtration rate of subjects with COPD as a tool for the early detection of the comorbidity of concealed chronic renal failure because COPD was positively associated with the estimated glomerular filtration rate and the COPD severity, Therefore, chronic renal failure should not be ignored or underestimated simply because it frequently cannot be recognized based on serum creatinine because the decrease in the estimated glomerular filtration rate is more prevalent.

according to the criteria of the 2015 Global Initiative for Obstructive Lung Disease. ${ }^{13}$ One hundred four healthy control subjects were recruited from the checkup program department of the October 6 University Hospital as a control group. Combined assessments of the COPD subjects according to the 2015 Global Initiative for Obstructive Lung Disease criteria were performed, ${ }^{13}$ and the COPD subjects were subdivided into 2 groups. Group 1 included 72 subjects in GOLD stages $\mathrm{A}$ and $\mathrm{B}$, and group 2 included 64 subjects in stages $\mathrm{C}$ and $\mathrm{D}$. The study was approved by the review board of the pulmonary medicine department of Ain Shams University, and written informed consent was obtained from all subjects.

\section{Exclusion Criteria}

The exclusion criteria for the COPD group were as follows: chronic comorbid disease, the receipt of corticosteroid therapy, and the presence of symptoms suggestive of exacerbation within the last month. The exclusion criteria for the control group were any chronic respiratory or nonrespiratory disease. The following data were collected from all participating subjects: full medical histories; clinical examinations; and anthropometric measures, including 
weight, height, calculated body mass index, chest radiography, electrocardiogram, pre- and post-bronchodilator spirometry, serum urea and creatinine, serum albumin, serum uric acid, calculated uric acid/creatinine ratio, and estimated glomerular filtration rate.

\section{Spirometry}

The spirometry tests were performed at Ain Shams University using an ENC Flowmate machine (Spirometrics, Spring Valley, New York) and at October 6 University using a Spirobank G-USB, class $\mathrm{II}_{\mathrm{a}}$, machine (MIR SRL, Rome, Italy). The tests were performed before and $20 \mathrm{~min}$ after $\beta_{2}$-agonist inhalation (salbutamol $400 \mu \mathrm{g}$ ) administered with a metered-dose inhaler. The pre- and post-bronchodilator spirometry parameters were measured according to the American Thoracic Society/European Respiratory Society standards in all subjects. ${ }^{14}$

\section{Estimated Glomerular Filtration Rate}

The estimated glomerular filtration rates were calculated using the modification of diet in renal disease equation: $170 \times$ serum creatinine $e^{-0.999} \times$ age $^{-0.176} \times$ blood urea $^{-0.170} \times$ serum albumin $^{0.318} \times(0.762$ for women $) \times(1.180$ for African-American subjects $) .15,16$

The subjects were classified concerning their renal function as having normal kidney function (glomerular filtration rate $\geq 60 \mathrm{~mL} / \mathrm{min} / 1.73 \mathrm{~m}^{2}$ ), concealed chronic renal failure (normal serum creatinine and glomerular filtration rate $<60 \mathrm{~mL} / \mathrm{min} / 1.73 \mathrm{~m}^{2}$ ), or overt chronic renal failure (increased serum creatinine and glomerular filtration rate $<60 \mathrm{~mL} / \mathrm{min} / 1.73 \mathrm{~m}^{2}$ ). A glomerular filtration rate of $<60 \mathrm{~mL} / \mathrm{min} / 1.73 \mathrm{~m}^{2}$ is the threshold for moderate kidney dysfunction of the Kidney Disease Outcomes Quality Initiative guideline classification. ${ }^{17}$ The cutoff value used for serum creatinine was $1.26 \mathrm{mg} / \mathrm{dL} .{ }^{18}$

\section{Data Analysis}

The data were compared using independent-sample $t$ tests for 2 groups and one-way analysis of variance tests with post hoc Bonferroni corrections or Kruskal-Wallis $\mathrm{H}$ tests for multiple groups. Simple correlations between variables were examined using Pearson's product correlation coefficient. SPSS 17 (SPSS, Chicago, Illinois) statistical software was used for the statistical analyses. All tests were considered significant at $P<.05$.

\section{Results}

The study was performed with 136 male subjects with COPD with a mean age of $60.3 \pm 5.2 \mathrm{y}$, and 104 healthy male subjects with a mean age of $59.9 \pm 5.3$ y served as
Table 1. Characteristic Data and Comparison Between Both Groups

\begin{tabular}{|c|c|c|c|}
\hline Characteristics & COPD & Control & $P$ \\
\hline Age, y & $60.3 \pm 5.2$ & $59.9 \pm 5.3$ & .88 \\
\hline Weight, kg & $64.69 \pm 13.79$ & $65.53 \pm 7.87$ & .58 \\
\hline Height, m & $1.70 \pm 0.06$ & $1.70 \pm 0.08$ & .96 \\
\hline BMI, $\mathrm{kg} / \mathrm{m}^{2}$ & $22.67 \pm 2.31$ & $22.75 \pm 3.25$ & .84 \\
\hline Pack-years & $36.59 \pm 23.2$ & $20 \pm 21.1$ & .15 \\
\hline Serum creatinine, $\mathrm{mg} / \mathrm{dL}$ & $0.93 \pm 0.22$ & $0.96 \pm 0.18$ & .35 \\
\hline $\begin{array}{l}\text { Estimated glomerular } \\
\text { filtration rate, } \\
\mathrm{mL} / \mathrm{min} \times 1.73 \mathrm{~m}^{2}\end{array}$ & $83.63 \pm 30.77$ & $197.88 \pm 79.89$ & $<.001$ \\
\hline FVC, $\%$ predicted & $57.39 \pm 23.1$ & $92.91 \pm 12.71$ & $<.00$ \\
\hline $\mathrm{FEV}_{1}, \%$ predicted & $53.11 \pm 22.48$ & $87.62 \pm 11.49$ & $<.00$ \\
\hline $\mathrm{FEV}_{1} / \mathrm{FVC}, \%$ predicted & $60.84 \pm 7.5$ & $84.47 \pm 9.32$ & $<.001$ \\
\hline MMEF, \% predicted & $42.58 \pm 23.68$ & $75.82 \pm 19.39$ & $<.001$ \\
\hline PEF, \% predicted & $46.51 \pm 19.96$ & $54 \pm 16.32$ & .07 \\
\hline \multicolumn{4}{|c|}{$\begin{array}{l}\text { Data are mean } \pm \text { SD. } \\
\text { BMI = body mass index } \\
\text { MMEF = maximum mid-expiratory flow } \\
\text { PEF = peak expiratory flow }\end{array}$} \\
\hline
\end{tabular}

the control group. The characteristic data and comparisons between the groups revealed significant differences between the COPD and control groups regarding estimated glomerular filtration rate and almost all of the spirometry parameters. There were no significant differences regarding age, weight, height, body mass index, smoking, or serum creatinine (Table 1).

Comparisons between the 2 COPD groups and the control group regarding anthropometric measures, serum creatinine, and the estimated glomerular filtration rate revealed no significant differences between the groups in the anthropometric data or serum creatinine, whereas significant differences between the 2 COPD groups and the control group in estimated glomerular filtration rate were observed (Fig. 1).

Comparisons of the clinical, laboratory, and spirometry data between groups 1 and 2 revealed significant differences in smoking; the modified Medical Research Council score for dyspnea; the COPD assessment test; the number of hospitalizations in the last year; laboratory data, including BUN, albumin, uric acid, and estimated glomerular filtration rate; and all of the post-bronchodilator spirometry data (Table 2).

The frequencies and percentages of normal kidney function, concealed chronic renal failure, and overt chronic renal failure in the COPD group, both COPD groups, and the control groups and the comparisons between the 3 groups (ie, group 1, group 2, and the control group) regarding renal status (ie, normal, concealed, or overt) are described and compared in Table 3.

The correlations of the serum creatinine level and estimated glomerular filtration rate with the clinical and spi- 


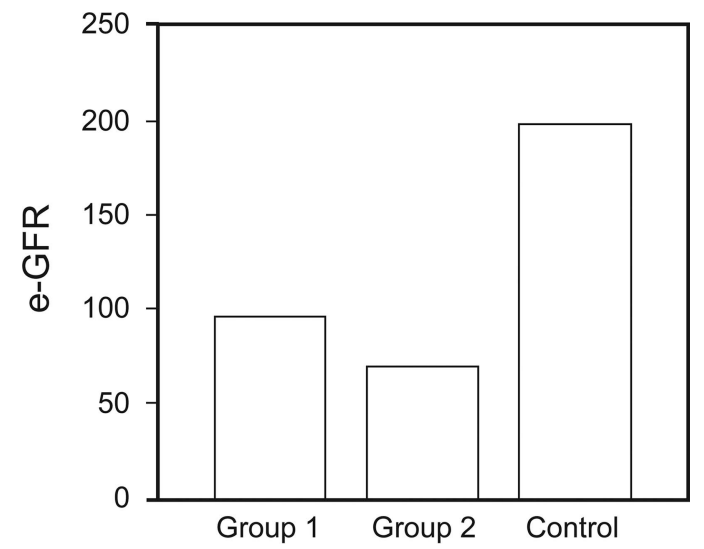

Fig. 1. Comparisons of the estimated glomerular filtration rates (e-GFR) of the 2 COPD groups and the control group revealing significant differences between group 1 ( $A$ and $B$ stages) and the control $(<.001)$, between group 2 ( $C$ and $D$ stages) and the control $(P<.001)$, and between group 1 and group $2(P<.001)$.

Table 2. Clinical, Laboratory, and Spirometry Data Comparison Between Group 1 and Group 2

\begin{tabular}{lccc}
\hline \hline \multicolumn{1}{c}{ Characteristics } & Group 1 & Group 2 & $P$ \\
\hline Pack-years & $41.9 \pm 24.7$ & $30.6 \pm 19.9$ & .004 \\
MMRC & $2.56 \pm 1.073$ & $3.63 \pm 1.23$ & $<.001$ \\
CAT & $18.94 \pm 6.66$ & $24.25 \pm 10.39$ & $<.001$ \\
Exacerbations, $n / \mathrm{y}$ & $2.28 \pm 1.416$ & $2.75 \pm 2.240$ & .14 \\
Hospitalizations, $n / \mathrm{y}$ & $1.17 \pm 1.13$ & $1.88 \pm 1.37$ & .001 \\
BUN, mg/dL & $23.28 \pm 13.27$ & $28 \pm 4.16$ & .007 \\
Albumin, mg/dL & $3.59 \pm 0.47$ & $3.2 \pm 0.39$ & $<.001$ \\
Uric acid, mg/dL & $5.38 \pm 0.88$ & $6.45 \pm 1.98$ & $<.001$ \\
Creatinine, mg/dL & $0.91 \pm 0.27$ & $0.95 \pm 0.13$ & .32 \\
UA/Cr & $6.31 \pm 1.83$ & $5.86 \pm 1.52$ & .12 \\
Estimated glomerular & $96.16 \pm 35.16$ & $69.54 \pm 15.94$ & $<.001$ \\
$\quad$ filtration rate, & & & \\
$\quad$ mL/min $\times 1.73$ m ${ }^{2}$ & & & \\
FVC, $\%$ predicted & $76.17 \pm 12.12$ & $36.28 \pm 11.07$ & $<.001$ \\
FEV,$\%$ predicted & $72.14 \pm 11.09$ & $31.71 \pm 8.09$ & $<.001$ \\
FEV $/$ FVC & $64.17 \pm 5.27$ & $57.09 \pm 7.9$ & $<.001$ \\
MMEF, \% predicted $_{\text {PEF, \% predicted }}^{56.24 \pm 21.14}$ & $27.2 \pm 15.63$ & $<.001$ \\
& $61.36 \pm 13.29$ & $29.81 \pm 10.92$ & $<.001$
\end{tabular}

Data are mean $\pm \mathrm{SD}$

MMRC $=$ Modified Medical Research Council dyspnea scale

$\mathrm{CAT}=\mathrm{COPD}$ assessment test

BUN $=$ blood urea nitrogen

$\mathrm{UA} / \mathrm{Cr}=$ uric acid/creatinine ratio

$\mathrm{MMEF}=$ maximum mid-expiratory flow

$\mathrm{PEF}=$ peak expiratory flow

rometry data were examined. There were significant correlations between the serum creatinine and COPD assessment test, and the number of exacerbations was correlated with the number of hospitalizations due to COPD exacerbation over the last year, the post-bronchodilator percent-of-predicted FVC and $\mathrm{FEV}_{1} / \mathrm{FVC}$, the percent-ofpredicted maximum mid-expiratory flow, and the percent-
Table 3. Frequency and Percentage of Normal Kidney Function, Concealed CRF, and Overt CRF in All Subjects With COPD, COPD Groups 1 and 2, and Control Group

\begin{tabular}{lrcccr}
\hline \hline & $n$ & Normal & Concealed & Overt & $P$ \\
\hline Total COPD & 136 & $100(73.53)$ & $27(19.85)$ & $9(6.62)$ & .035 \\
Group 1 & 72 & $64(88.9)$ & $7(9.72)$ & $1(1.38)$ & .003 \\
Group 2 & 64 & $45(70.31)$ & $11(17.19)$ & $8(12.50)$ & \\
Control & 104 & $102(98.08)$ & $2(1.92)$ & $0(0)$ & \\
\hline Data are $n(\%)$. & & & & & \\
\hline
\end{tabular}

Table 4. Correlation Between Serum Creatinine, e-GFR and Clinical, Spirometry Data

\begin{tabular}{|c|c|c|}
\hline & \multicolumn{2}{|c|}{$P$} \\
\hline & Creatinine & $\begin{array}{c}\text { Estimated } \\
\text { Glomerular } \\
\text { Filtration Rate }\end{array}$ \\
\hline MMRC & .08 & $<.001$ \\
\hline CAT & .01 & $<.001$ \\
\hline Exacerbations $(n / y)$ & .005 & .001 \\
\hline Hospitalizations $(n / y)$ & .004 & $<.001$ \\
\hline FVC (\% predicted) & .003 & $<.001$ \\
\hline $\mathrm{FEV}_{1}(\%$ predicted $)$ & .060 & $<.001$ \\
\hline $\mathrm{FVC} / \mathrm{FEV}_{1}$ ratio ( $\%$ predicted) & .01 & $<.001$ \\
\hline MMEF (\% predicted) & .03 & $<.001$ \\
\hline PEF (\% predicted) & .007 & $<.001$ \\
\hline \multicolumn{3}{|c|}{$\begin{array}{l}\text { MMRC = Modified Medical Research Council dyspnea scale } \\
\text { CAT }=\text { COPD assessment test } \\
\text { MMEF = maximum mid-expiratory flow } \\
\text { PEF = peak expiratory flow }\end{array}$} \\
\hline
\end{tabular}

of-predicted peak expiratory flow. The estimated glomerular filtration rate was also correlated with all of the clinical and spirometry data (Table 4).

\section{Discussion}

The present study demonstrated that renal impairment is more frequent among subjects with COPD than non-COPD control subjects without comorbidities. The estimated glomerular filtration rate is frequently depressed in COPD subjects, despite normal serum creatinine levels in both groups. A previous study concluded that the estimated prevalence of chronic renal failure in a population with COPD was greater than that observed in a control population without COPD and with a comparable comorbidity burden. ${ }^{19}$

The results of other studies also agree with the present results, but those studies systematically assessed chronic renal failure in unselected populations with COPD and found that chronic renal failure is prevalent and predictive 
of long-term mortality. However, the diagnoses of chronic renal failure in these studies were based on serum creatinine, and thus its prevalence was probably underestimated. ${ }^{2}$

Indeed, patients with COPD exhibit reduced muscle mass ${ }^{12}$; thus, the serum creatinine levels might be falsely low as the result of decreased creatine release. ${ }^{6}$ This decrease was verified by Yoshizawa et al, ${ }^{20}$ who found that the estimated glomerular filtration rate did not differ between the COPD and non-COPD groups when an estimation formula based on serum creatinine was used, but the COPD group exhibited significantly reduced estimated glomerular filtration rate when a formula based on serum cystatin $\mathrm{C}$ was employed.

However, the results of the present study verified that the COPD subjects exhibited no significant increase in serum creatinine level compared with the control subjects. Interestingly, there were significant correlations of the serum creatinine level with most of the spirometry parameters, with the COPD assessment test clinical assessment tool for COPD, and with the numbers of hospitalizations and exacerbations. The estimated glomerular filtration rate was significantly lower in the subjects with COPD.

Moreover, COPD was positively associated with concealed and overt chronic renal failure compared with the control subjects. This relationship was verified by the strength of the association of COPD severity, reflected by the spirometry measurements, with the worsening of symptoms and the low estimated glomerular filtration rate. Therefore, COPD is significantly associated with chronic renal failure comorbidity, as proven by different studies. ${ }^{21,22}$

The present study subdivided the subjects according to renal status into normal, concealed, and overt renal failure groups. Comparisons of the distributions of the subjects in each group revealed that the number of subjects with concealed renal failure was significantly higher among the subjects with COPD than among the control subjects and that the clinical statuses, spirometry parameters, and number of concealed renal failure cases in the group 2 COPD subjects were significantly worse than those of both the control group and the COPD group 1 .

The significant increase in the number of concealed rather than overt renal failure cases among group 2 subjects verifies the idea that renal impairment is remarkably underestimated as a COPD comorbidity and indicates the importance of estimating the glomerular filtration rate of COPD patients as an early indication of the probably of the future development of the comorbidity of concealed chronic renal failure.

The high prevalence of chronic renal failure in patients with COPD might have important clinical implications. A previous study proved the associations of chronic renal failure with increased serum levels of inflammatory biomarkers and prothrombotic molecules that are increased in subjects with COPD. ${ }^{23}$
Moreover, chronic renal failure, both overt and concealed, is a well-known risk factor for adverse reactions to hydrosoluble drugs. Indeed, most of the antibiotics that are commonly used for exacerbated COPD are cleared by the kidney, as are the drugs that are frequently used to treat comorbid conditions (eg, thiazides for hypertension and digoxin for atrial fibrillation). ${ }^{24}$ Other studies suggest that chronic renal failure might aid in the understanding of the link between COPD and anemia. ${ }^{25,26}$

This study has some limitations. Chronic renal failure was diagnosed based on the estimated glomerular filtration rate, which was calculated from the serum creatinine, and the diagnoses were made without comparisons with diagnoses made using other methods, such as those based on microalbuminuria and serum cystatin $\mathrm{C}$ measurements or other parameters for insurance coverage-related purposes. Moreover, assessments of microalbuminuria could not be performed because the subjects included in this study were collected from out-patient departments, which made the accurate collection of urine over $24 \mathrm{~h}$ difficult. Moreover, this study did not involve measurements of the muscle masses of the included subjects, but this factor might have influenced the serum creatinine values and thus the estimated glomerular filtration rates.

\section{Conclusions}

In the context of the increasing interest in systemic features of COPD and related comorbidities, chronic renal failure should not be ignored or underestimated simply because it frequently cannot be recognized based on serum creatinine because decreases in estimated glomerular filtration rates are more prevalent.

\section{REFERENCES}

1. van Manen JG, Bindels PJ, Dekker FW, Bottema BJ, van der Zee JS, Ijzermans CJ, and Schadé E. The influence of COPD on healthrelated quality of life independent of the influence of comorbidity. J Clin Epidemiol 2003;56(12):1177-1184.

2. Antonelli Incalzi R, Fuso L, De Rosa M, Forastiere F, Rapiti E, Nardecchia B, and Pistelli R. Co-morbidity contributes to predict mortality of patients with chronic obstructive pulmonary disease. Eur Respir J 1997;10(12):2794-2800.

3. Salonen JT, Salonen R. Ultrasound B-mode imaging in observational studies of atherosclerotic progression. Circulation 1993;87(3 Suppl): II56-II65.

4. Orth SR, Ritz E, Schrier RW. The renal risks of smoking. Kidney Int 1997;51(6):1669-1677.

5. Myers GL, Miller WG, Coresh J, Fleming J, Greenberg N, Greene T, et al. Recommendations for improving serum creatinine measurement: a report from the Laboratory Working Group of the National Kidney Disease Education Program. Clin Chem 2006;52(1):5-18.

6. Rule AD, Larson TS, Bergstralh EJ, Slezak JM, Jacobsen SJ, Cosio FG. Using serum creatinine to estimate glomerular filtration rate: accuracy in good health and in chronic kidney disease. Ann Int Med 2004;141(12):929-937. 


\section{COPD AND COMORBID RENAL IMPAIRMENT}

7. Coresh J, Selvin E, Stevens LA, Manzi J, Kusek JW, Eggers P, et al. Prevalence of chronic kidney disease in the United States. JAMA 2007;298(17):2038-2047.

8. Souza SP, Matos RS, Barros LL, Rocha PN. Inverse association between serum creatinine and mortality in acute kidney injury. J Bras Nefrol 2014;36(4):469-475.

9. Orth SR. Effects of smoking on systemic and intrarenal hemodynamics: influence on renal function. J Am Soc Nephrol 2004;15(Suppl 1):S58-S63.

10. Gupta RK, Gupta R, Maheshwari VD, Mawliya M. Impact of smoking on microalbuminuria and urinary albumin creatinine ratio in non-diabetic normotensive smokers. Indian J Nephrol 2014;24(2): 92-96.

11. Preston RA, Epstein M. Ischemic renal disease: an emerging cause of chronic renal failure and end-stage renal disease. J Hypertens 1997;15(12):1365-1377.

12. Ischaki E, Papatheodorou G, Gaki E, Papa I, Koulouris N, Loukides S. Body mass and fat-free mass indices in COPD: relation with variables expressing disease severity. Chest 2007;132(1):164-169.

13. Mapel DW, Dalal AA, Johnson PT, Becker LK, Hunter AG. Application of the new GOLD COPD staging system to a US primary care cohort, with comparison to physician and patient impressions of severity. Int J Chron Obstruct Pulmon Dis 2015;10:1477-1486.

14. Miller MR, Hankinson J, Brusasco V, Burgos F, Casaburi R, Coates A, et al. Standardisation of spirometry. Eur Respir J 2005;26(2):319338.

15. Levey AS, Bosch JP, Lewis JB, Greene T, Rogers N, Roth D. A more accurate method to estimate glomerular filtration rate from serum creatinine: a new prediction equation. Ann Int Med 1999; 130(6):461-470.

16. Stevens LA, Coresh J, Greene T, Levey AS. Assessing kidney function: measured and estimated glomerular filtration rate. N Engl J Med 2006;354(23):2473-2483
17. Kopple JD. National Kidney Foundation K/DOQI clinical practice guidelines for nutrition in chronic renal failure. Am J Kidney Dis 2001;37(1):S66-S70.

18. Jones CA, McQuillan GM, Kusek JW, Eberhardt MS, Herman WH, Coresh J, et al. Serum creatinine levels in the US population: third National Health and Nutrition Examination Survey. Am J Kidney Dis 1998;32(6):992-999.

19. Incalzi RA, Corsonello A, Pedone C, Battaglia S, Paglino G, Bellia V. Chronic renal failure: a neglected comorbidity of COPD. Chest 2010;137(4):831-837.

20. Yoshizawa T, Okada K, Furuichi S, Ishiguro T, Yoshizawa A, Akahoshi T, et al. Prevalence of chronic kidney diseases in patients with chronic obstructive pulmonary disease: assessment based on glomerular filtration rate estimated from creatinine and cystatin C levels. Int J Chron Obstruct Pulmon Dis 2015;10:1283-1289.

21. Almagro P, Calbo E, Ochoa de Echagüen A, Barreiro B, Quintana S, Heredia JL, Garau J. Mortality after hospitalization for COPD. Chest 2002;121(5):1441-1448

22. Bellia V, Pistelli R, Catalano F, Antonelli-Incalzi R, Grassi V, Melillo G, et al. Quality control of spirometry in the elderly: the SA.R.A. study. Am J Respir Crit Care Med 2000;161(4):1094-1100.

23. Shlipak MG, Fried LF, Crump C, Bleyer AJ, Manolio TA, Tracy RP, et al. Elevations of inflammatory and procoagulant biomarkers in elderly persons with renal insufficiency. Circulation 2003;107(1):87-92.

24. Corsonello A, Pedone C, Corica F, Mussi C, Carbonin P, Antonelli Incalzi R, Gruppo Italiano di Farmacovigilanza nell'Anziano (GIFA) Investigators. Concealed renal insufficiency and adverse drug reactions in elderly hospitalized patients. Arch Int Med 2005;165(7):790-795.

25. Cote C, Zilberberg MD, Mody SH, Dordelly LJ, Celli B. Haemoglobin level and its clinical impact in a cohort of patients with COPD. Eur Respir J 2007;29(5):923-929.

26. John M, Hoernig S, Doehner W, Okonko DD, Witt C, Anker SD. Anemia and inflammation in COPD. Chest 2005;127(3):825-829. 